\title{
Sorting out adipocyte precursors and their role in physiology and disease
}

\author{
Chelsea Hepler, Lavanya Vishvanath, and Rana K. Gupta \\ Touchstone Diabetes Center, Department of Internal Medicine, University of Texas Southwestern Medical Center, \\ Dallas, Texas 75390, USA
}

\begin{abstract}
The ability to maintain and expand the pool of adipocytes in adults is integral to the regulation of energy balance, tissue/stem cell homeostasis, and disease pathogenesis. For decades, our knowledge of adipocyte precursors has relied on cellular models. The identity of native adipocyte precursors has remained unclear. Recent studies have identified distinct adipocyte precursor populations that are physiologically regulated and contribute to the development, maintenance, and expansion of adipocyte pools in mice. With new tools available, the properties of adipocyte precursors can now be defined, and the regulation and function of adipose plasticity in development and physiology can be explored.
\end{abstract}

Adipocytes ("fat cells") are critical regulators of several aspects of normal physiology, including energy balance, nutrient homeostasis, and tissue homeostasis (Rosen and Spiegelman 2014). White adipocytes represent the principle site for energy storage in mammals. These cells accumulate excess energy in the form of intracellular triglycerides packaged into large single lipid droplets. White adipocytes are also endocrine cells; adipocytes secrete numerous hormones and cytokines that impact several aspects of physiology, including nutrient homeostasis, inflammation, and reproductive biology (Ouchi et al. 2011). Classical brown (referred to here as "brown") and beige/BRITE (referred to here as "beige") adipocytes comprise a second major class of adipocytes that function to convert chemical energy into heat. They are characterized by their abundance of mitochondria, multilocular fat droplet appearance, and specific expression of uncoupling protein 1 (UCP1) (Rosen and Spiegelman 2014). Brown adipose tissue (BAT) likely evolved to help defend animals against the cold. Historically, BAT has been referred to as the "hibernating organ" due to its function in maintaining body temperature in hibernating animals and newborns. Beyond its role in regulating thermogenesis, brown and beige adipocytes have a major role in regulating

[Keywords: adipocyte precursor; adipogenesis; beige adipocytes; brown adipocytes; white adipocytes]

Corresponding author: rana.gupta@utsouthwestern.edu

Article is online at http://www.genesdev.org/cgi/doi/10.1101/gad.293704. 116. glucose and lipid homeostasis (Seale et al. 2011; Kajimura et al. 2015; Shao et al. 2016).

Interest in adipocyte biology has increased dramatically over the last 20 years, coincident with the global obesity epidemic and the realization that adipocytes play a broader role in physiology than envisioned previously (Rosen and Spiegelman 2014). The field has witnessed great progress in revealing the many functions of adipocytes in physiology; however, the basic developmental biology of adipose tissue has lagged behind. Below, we highlight recent efforts to identify native adipose precursor populations that contribute to adipose development and the physiological recruitment of white, brown, and beige adipocytes in postnatal animals. We focus primarily on recent insight gained from mouse studies and discuss new tools that will help the field move forward. Furthermore, we summarize new data that reveal the complexities of adipose tissue development and expansion in vivo.

\section{Development of white adipocytes and their precursors}

Anatomical distribution of white adipose depots and fetal origins

Some of the earliest studies of adipocyte development dated back to the late 19th century. Notable anatomists such as Toldt and Flemming expressed seemingly opposing views of the origin of adipocytes (discussed by Wasserman 1965, republished in Wasserman 2011). Flemming argued that adipocytes originated from loose connective tissue and that nearly all fibroblast-like cells had the capacity to become lipid-laden cells. As such, Flemming implied that adipocytes were not truly distinct cells worth considerable observation. Toldt and, later, Wasserman believed that adipose tissue, like other tissues and organs, followed a developmental pattern in which fat cells emerge from specific precursor cells at select time points. In particular, seminal work from Wasserman (1926) and others illustrated that adipocytes first emerge in conjunction with dense

(C) 2017 Hepler et al. This article is distributed exclusively by Cold Spring Harbor Laboratory Press for the first six months after the full-issue publication date (see http://genesdev.cshlp.org/site/misc/terms.xhtml). After six months, it is available under a Creative Commons License (Attribution-NonCommercial 4.0 International), as described at http:// creativecommons.org/licenses/by-nc/4.0/. 
networks of blood vessels, forming what was called the "primitive organ." In recent years, a number of studies have used modern molecular/genetic approaches to demonstrate the dependence of adipocytes on angiogenesis for tissue development (Han et al. 2011; Hong et al. 2015). In fact, some studies have suggested a possible endothelial origin of adipocytes; however, reported lineage tracing studies are conflicting (Tran et al. 2012; Berry and Rodeheffer 2013).

White adipocytes are found throughout the body; however, they are generally organized into distinct tissues or "depots." Today, it is clear that adipose tissues emerge and develop in a specific spatiotemporal manner. Adipose depots are broadly classified as "subcutaneous" or "visceral," reflecting their general anatomical localization; however, each individual subcutaneous or visceral depot develops at different fetal stages. In humans, nascent adipose tissue first appears in the second trimester of gestation as "primitive fat lobules" that accumulate first in the head and neck, then in the trunk, and later in the limbs (Poissonnet et al. 1984). Likewise, murine white adipose depots are specified and develop at various stages of life (Han et al. 2011; Jiang et al. 2014). Subcutaneous inguinal adipocytes emerge perinatally; most intra-abdominal depots take form after birth (Wang et al. 2013).

The precise developmental origin of white adipose tissue (WAT) during fetal development is still unclear; however, lineage tracing in mice indicates that subcutaneous and intra-abdominal depots emanate from distinct mesenchymal lineages (Chau et al. 2014). Adipocytes in visceral, but not subcutaneous or brown, adipose depots descend from cells expressing the mesothelial cell marker Wilms tumor 1 (WT1). These data suggest the lateral plate mesoderm as the fetal origin of visceral adipose tissues. However, the precise origin of adipose tissue may vary from depot to depot. For instance, in mice, craniofacial, but not peripheral, subcutaneous WAT depots originate from neuroectoderm rather than mesodermal structures (Billon and Dani 2012). Adding to the complexity, individual depots may contain adipocytes that arise through distinct lineages (Sanchez-Gurmaches and Guertin 2014). Molecular and cellular studies indicate that anatomically distinct depots are also functionally distinct and express differing molecular programs (Macotela et al. 2012; Wu et al. 2012; Lee et al. 2013; Morgan-Bathke et al. 2015). As a result, the simple designation of white adipocytes as "subcutaneous" or "visceral" is likely too simplistic. Each anatomically distinct depot may actually represent a developmentally and functionally distinct form of adipose tissue.

\section{Maintenance and expansion of WAT in adults}

During the first year of life, adipose tissue continues to expand considerably through cellular hypertrophy and the recruitment of new adipocytes (cellular hyperplasia) (Knittle et al. 1979). In adulthood, adipocyte turnover occurs at a rate of $\sim 10 \%$ per year (Spalding et al. 2008). In rodents, the degree of turnover may be higher, varying from depot to depot (Wang et al. 2013; Rivera-Gonzalez et al. 2016). A remarkable and unique property of adipose tissue is the tremendous capacity to expand or contract in different physiological settings. The capacity to expand is most evident in the setting of obesity, where adipose tissue mass can reach upward of $60 \%$ of body weight in the morbidly obese (Ortega et al. 2010). The ability of adipose tissue to shrink and then re-expand is perhaps best highlighted by the response of mammary adipose tissue to pregnancy and lactation. During pregnancy and the lactation period, adipocytes are replaced by milk-producing alveolar structures and then reappear as the alveolar structures involute at weaning (Cinti 2009).

The manner by which adipose tissue expands is of great clinical significance (for review, see Hepler and Gupta 2016). Preferential expansion of subcutaneous depots is associated with protection against cardiometabolic disease in obesity (Lee et al. 2013; Karpe and Pinnick 2015). Preferential expansion of visceral depots correlates well with insulin resistance and diabetes. Moreover, expansion of adipose tissue mass through adipocyte hyperplasia is more metabolically favorable than through an increase in cell size (hypertrophy) (Lee et al. 2010). Hyperplasia occurs through the recruitment of adipocyte precursors that undergo adipogenesis and is associated with adipose health and a delayed onset of insulin resistance. As such, de novo adipocyte differentiation in adults appears critical for the maintenance and expansion of adipose depots (Gustafson et al. 2009).

Lineage tracing studies have revealed that the mode of adipose depot expansion in mice fed a high-fat diet occurs in a depot- and sex-dependent manner (Wang et al. 2013; Kim et al. 2014; Jeffery et al. 2015). Epididymal adipose expansion in adult male mice fed a high-fat diet occurs through both adipocyte hypertrophy and hyperplasia, while the inguinal (subcutaneous) depot in these same animals expands almost exclusively through cellular hypertrophy (Wang et al. 2013). In female mice, adipocyte hyperplasia occurs in both the perigonadal WAT and, to some variable extent, the inguinal WAT (Jeffery et al. 2016). A better understanding of how adipose precursors are activated in obesity may lead to therapeutic strategies to alter body fat distribution and/or adipose tissue health.

In recent years, it has become increasingly clear that adipocyte accumulation in areas beyond the major depots plays an important role in physiology and pathology (Shook et al. 2016). Adipocytes accumulate in the skin below the dermis (dermal WAT, referred to here as "dWAT") and play a critical role in dermal homeostasis (Alexander et al. 2015; Kruglikov and Scherer 2016). This relatively unexplored depot expands in response to cold exposure, wounding, and bacterial infection. Adipose lineage cells in the skin also respond to hair follicle cycling and regulate follicle homeostasis (Festa et al. 2011). Marrow adipose tissue (MAT), located in various skeletal regions, appears to contribute to local skeletal remodeling, hematopoietic regulation, and systemic metabolism (Scheller et al. 2016). Marrow adipocytes are a developmentally distinct white adipocyte population. MAT, but not other WAT depots, is derived from cells once expressing Osx1 (Berry et al. 2015). MAT expansion occurs in response to various pharmacological or physiological triggers, such 
as glucocorticoids, anti-diabetic thiazolidinediones, estrogen deficiency, obesity, and aging. Likewise, adipocytes also accumulate in the skeletal muscle at sites of injury (Joe et al. 2010; Uezumi et al. 2010). The accumulation of adipocytes in skeletal muscle can impact the regenerative capacity and function of muscle. Similarly, a defining feature of arrhythmogenic cardiomyopathy is the progressive replacement of the myocardium with fibrous tissue and adipocytes (Samanta et al. 2016). The developmental origin and exact properties and function of these lesserstudied adipocytes are still being unraveled; however, it is clear that the ability of new adipocytes to emerge in these tissues is critical for tissue homeostasis and perhaps systemic metabolism.

\section{White adipocyte precursors: in vitro models}

Much of our knowledge of the cellular aspects of adipocyte differentiation emanate from the use of cell culture models. Mouse embryonic fibroblasts (MEFs) from midstage to late stage embryos can be readily induced to undergo adipogenesis in response to a hormonal/pharmacological cocktail consisting of dexamethasone, iso-butylmethyl-xanthine, and insulin. This observation lends credence to the views of Flemming that adipocytes can and readily do emerge from ubiquitous fibroblast-like cells. Similarly, adherent fibroblast-like cells within cultures of the adipose stromal vascular fraction (SVF) have been propagated and differentiated into mature adipocytes in vitro (Poznanski et al. 1973; Van et al. 1976; Van Robin and Roncari 1977). Other mesenchymal lineages, such as osteoblasts, myoblasts, and chondrocytes, can also differentiate from cultures of the adherent adipose SVF (Cawthorn et al. 2012). As such, the adherent SVF from adipose tissue is often described as "adipose stem cells" or "mesenchymal stem cells" (Cawthorn et al. 2012). Importantly, cultured MEFs or SVF cells are heterogeneous; whether these cultures contain cells that truly reflect native adipocyte precursors is not certain.

In the 1970s, Green and Kehinde (1974) derived 3T3-L1 cells as a clonal subline of $3 \mathrm{~T} 3$ immortalized MEFs from Swiss mice. 3T3-L1 cells are viewed as being a "determined" preadipocyte cell line; the cells are morphologically indistinguishable from less adipogenic or nonadipogenic fibroblasts but are highly committed to the adipocyte lineage. The isolation of such committed cells implied that preadipocytes were specialized fibroblasts with a stably unique molecular program. Preadipocyte cell lines have been powerful models for the study of adipocyte determination and differentiation. Ppar $\gamma$, the "master regulator" of adipocyte differentiation, was originally discovered through the use of 3T3 cells (Chawla and Lazar 1994; Tontonoz et al. 1994). Today, there are dozens of transcriptional regulators implicated in the process of 3T3-L1 adipocyte differentiation. Excellent reviews have been written on this matter (Farmer 2006; Cristancho and Lazar 2011); however, it is now clear that anatomically distinct adipocytes represent, at least to some degree, distinct lineages. As such, whether cultured preadipocyte cell lines represent any particular type of native adipocyte precursor remains unclear. Here, we summarize recent efforts to identify and characterize native adipose precursors, highlighting their regulation and potential contribution to the adipose lineage and physiology (summarized in Fig. 1).

Native adipocyte precursors: identity, regulation, and function

$C D 24^{+}$and $C D 24^{-}$adipocyte progenitor cells Several years ago, Friedman and colleagues (Rodeheffer et al. 2008) developed a strategy to prospectively purify adipocyte progenitor cells (APCs) from freshly isolated murine adipose SVFs. These investigators combined antibodies raised against combinations of accepted stem cell cell surface proteins with fluorescent-activated cell sorting (FACS) to isolate and characterize two functionally distinct APC subpopulations. Both populations are devoid of endothelial and hematopoietic markers (CD31 and CD45, respectively) and positive for common mesenchymal stem cell markers Sca1, CD34, and CD29 but distinguishable by the expression of CD24. The CD24 ${ }^{+}$APCs represent a highly proliferative and stem cell-like primitive adipose progenitor population, whereas CD24- APCs appear to represent a more committed "preadipocyte" population that expresses lineage-selective genes such as Ppar 2 and C/ebpa. CD24+ APCs give rise to CD24- $\mathrm{APCs}$ in vivo during development, en route to adipocyte differentiation (Berry and Rodeheffer 2013). These data reveal the existence of hierarchical populations of adipose precursors exhibiting different levels of commitment.

In adult animals, CD $24^{+} \mathrm{APC}$ are relatively rare in comparison with the more committed CD24- $\mathrm{APC}$ population; however, the $\mathrm{CD} 24^{+}$population appears highly regulated by a number of physiological settings. The frequency of these cells is relatively higher in lipodystrophic animals (Rodeheffer et al. 2008). In addition, CD24 $4^{+}$APCs are regulated by high-fat diet feeding in a sex- and depot-dependent manner (Jeffery et al. 2015, 2016). CD $24^{+}$APCs undergo rapid and transient proliferation within days of high-fat diet feeding, selectively in depots exhibiting a hyperplastic response. Importantly, these data suggest that adipocyte precursor proliferation is triggered by diet rather than obesity per se. Transplantation studies indicate that the abilities of precursors to proliferate and undergo differentiation upon high-fat diet feeding are largely regulated by the local microenvironment (Jeffery et al. 2016). The notion that depot-specific signals control local adipogenesis is highlighted by recent studies of dWAT, where CD24 $4^{+}$ APCs are present and undergo proliferation and differentiation in association with hair follicle cycling (Rivera-Gonzalez et al. 2016). Maintenance of the CD24 ${ }^{+}$APC pool in dWAT, but not in gonadal or inguinal WAT, is dependent on local Pdgfa (platelet-derived growth factor $\alpha$ ) signaling. Moreover, hair follicle transit-amplifying cells regulate proliferation of $\mathrm{CD}_{2} 4^{+} \mathrm{APCs}$ and dermal adipogenesis through secretion of sonic hedgehog (Zhang et al. 2016).

The FACS-based method to isolate CD24+ $4^{+}$and CD24APCs provides a convenient approach to purify and study 
Hepler et al.

A

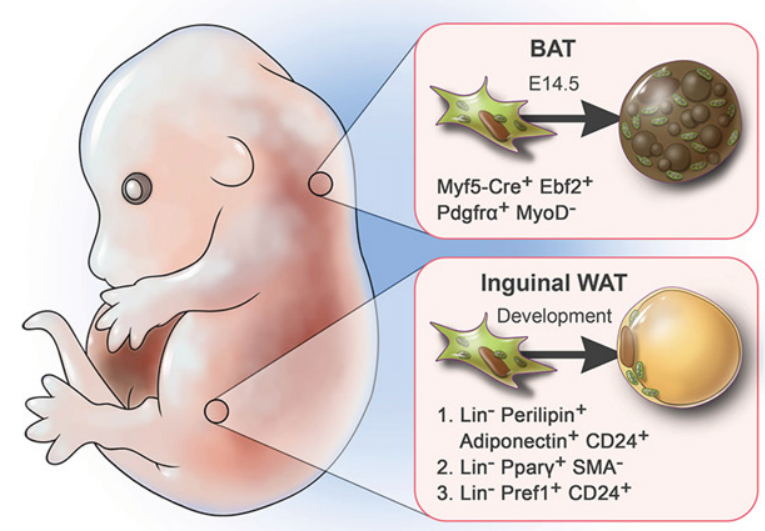

B

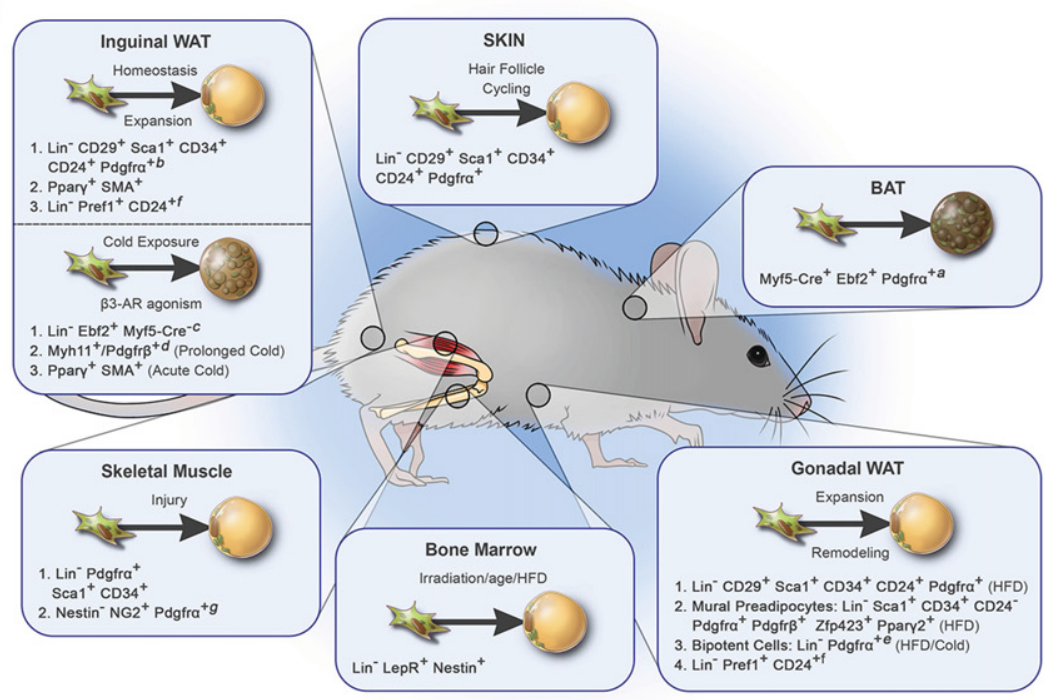

Footnotes:

a. Contribution to maintenance and expansion of BAT in adults is unclear.

b. Cells contribute to adipocyte hyperplasia in females but not in males undergoing high fat diet feeding.

c. Highly committed to beige lineage upon cold exposure; however, lineage tracing not yet reported. Localization in WAT is unknown.

d. Lineage tracing indicates beige cells arise from cells expressing these markers after 2 weeks of cold exposure; exact beige precursor subpopulation has not been purified.

e. Gonadal Pdgfra+ cells are bipotent in vitro, giving rise to both white and UCP1+ adipocytes.

f. Adipose expansion upon HFD depends on these cells; however, lineage tracing not reported.

g. Two types of pericytes have been characterized in the injured skeletal muscle using transgenic reporter mice: Nestin-GFP-ING2-DsRed ${ }^{+}$(type-1) and Nestin-GFP+/NG2-DsRed (type-2). Type 1 pericytes express Pdgfra. Type-2 pericytes participate in muscle regeneration, while type-1 contribute to fat accumulation.

Figure 1. Adipocyte precursor heterogeneity in mice. $(A)$ Characterized fetal adipose precursor populations: Three adipose progenitor populations have been characterized in the developing inguinal WAT depot. The degree of overlap in these populations is unclear. Seale and colleagues (Wang et al. 2014) have identified a brown adipocyte progenitor population in BAT that is marked by myogenic factor 5 (Myf5)-Cre and expresses platelet-derived growth factor a (Pdgfra) and Ebf2. These cells emerge at embryonic day 10.5 (E10.5) and are devoid of MyoD at this stage, suggesting that brown adipocyte lineage commitment has already occurred. $(B)$ Tissue-resident adipose precursors in adult mice: Adipose precursor populations have been identified in multiple tissues and are listed as they were identified and characterized. There is likely a degree of overlap in the populations. Additional populations may exist based on published lineage tracing results.

adipose precursors from various rodent models with easily obtainable commercial reagents. One limitation to the approach lies in the inability to visualize these cells in vivo in their natural environment; multiple cell surface markers are needed to detect these specific cells. As such, it is still unclear where CD24 $4^{+}$APCs reside and are regulated 
within the adipose depots. Recently reported BrdU-based "pulse-chase" lineage tracing experiments indicate a contribution of CD24+ APCs to adipocyte hyperplasia in obesity (Jeffery et al. 2015, 2016); however, it remains unclear to what extent adipocyte differentiation originates from the $\mathrm{CD}_{2} 4^{+}$versus CD24- $\mathrm{APC}$ population. As pointed out by Jeffery et al. (2016), most newly formed adipocytes accumulating following the onset high-fat diet feeding appear to originate from nonproliferating APCs. More precise lineage tracing and manipulation of $\mathrm{CD} 24^{+}$cells is needed to better understand their requirement in adult physiology.

Pdgfra ${ }^{+}$cells There has long been interest in identifying muscle-resident precursors for adipocytes and fibrocytes accumulating in injured skeletal muscle. In 2010, independent studies from the laboratories of Uezumi et al. (2010) and Joe et al. (2010) reported the presence of a population of stromal cells distinct from muscle progenitors that give rise to fibroblasts and adipocytes upon chemical-induced muscle injury in mice. These cells, termed "fibroadipogenic progenitors" (FAPs), can be identified by the expression of Pdgfra along with Sca1 and CD34 and are activated to proliferate in response to injury. Interestingly, transplantation assays revealed that FAPs differentiate into adipocytes upon transplantation into injured, but not healthy, skeletal muscle. These data further highlight the importance of the microenvironment in dictating a proadipogenic response.

Granneman and colleagues (Lee et al. 2012) focused on identifying thermogenic adipocyte precursors in adipose depots that respond to $\beta 3$ adrenergic receptor ( $\beta 3 \mathrm{AR}$ ) signaling. Proliferating precursors stimulated by $\beta 3 \mathrm{AR}$ activation can be defined also by the expression of Pdgfra ${ }^{+}$; $\mathrm{CD} 4^{+} ; \mathrm{Sca}^{+}$. These cells are bipotent in vitro-capable of differentiating into white and beige adipocytes. Pdgfra ${ }^{+}$ progenitors reside in close proximity to capillaries but have dendritic processes that extend away from the vasculature and do not share a basement membrane with endothelial cells. Importantly, lineage tracing indicated that newly formed adipocytes emerging in response to highfat diet feeding descend from cells expressing Pdgfra. In fact, nearly all adipocytes in the body reside within the Pdgfra lineage (i.e., targeted by Pdgfra-Cre), and CD $24^{+}$ and CD24- APCs actively express this marker (Berry and Rodeheffer 2013). As such, the isolation of Pdgfra ${ }^{+}$; CD $31^{-}$;CD45 ${ }^{-}$cells represents a convenient strategy to enrich for adipose precursors within adipose depots and other tissues.

Adipose tissue mural cells Another approach commonly used to locate stem/progenitor populations is to follow the expression of lineage-determining factors. Graff and colleagues (Tang et al. 2008) reasoned that the expression of Ppary, the most critical adipogenic factor, would facilitate the identification of adipose precursors. Tang et al. (2008) generated reporter mice in which the Ppary locus drives GFP or LacZ expression. The investigators demonstrated that Ppar $^{+}$cells reside within the blood vessel walls of adult WAT and resemble mural cells (pericytes and vascular smooth muscle cells). These cells express several mural cell markers, such as Pdgfr $\beta$, NG2 (neural/ glial antigen 2), and SMA ( $\alpha$ smooth muscle actin). Furthermore, they uniformly express CD34 and Sca1. Importantly, these cells contribute to WAT homeostasis in lean mice (chow-fed), with an estimate of $10 \%-20 \%$ of new adipocytes forming per month depending on the WAT depots examined (Tang et al. 2008; Jiang et al. 2014). This observation was significant, since it provided the first molecular evidence of the hypotheses put forth by Wasserman (1960) and others (Napolitano 1963; Cinti et al. 1984) decades ago that adipose progenitors reside in or near the vasculature of adipose tissue and resemble pericytes. These data provide evidence that the adipocyte precursor niche is created by the microenvironment of the vasculature.

The hypothesis of a perivascular origin of adipogenesis is also supported by mural cell expression of $Z f p 423$ (Gupta et al. 2012; Vishvanath et al. 2016). Zfp423 is a multizinc finger transcription factor that regulates preadipocyte Ppary expression and adipocyte differentiation in vitro and in vivo (Gupta et al. 2010). Using Zfp423 reporter mice (transgenic $Z f p 423^{\mathrm{GFP}}$ reporter mice), we localized the expression of GFP to a distinct subset of endothelial and mural cells in adipose depots (Gupta et al. 2012). Nonendothelial $Z f p 423^{+}$stromal cells express the mural cell marker Pdgfr $\beta$ as well as the aforementioned APC markers Pdgfra, CD34, and Sca1. The expression of Ppary and other adipose lineage-selective genes is enriched in Zfp423 ${ }^{+}$mural cells (Vishvanath et al. 2016). Furthermore, most $\mathrm{Zfp} 423^{+}$mural cells were devoid of CD24 expression, suggesting that they are among the committed preadipocyte population. The enrichment of Ppary suggests that this population at least overlaps with the mural cell population examined by Graff and colleagues (Tang et al. 2008). Zfp423 ${ }^{+}$mural cells undergo adipocyte differentiation in vitro more readily than $\mathrm{Zfp} 43^{-}$ mural cells. Importantly, the abundance of Zfp $423^{+}$mural cells is physiologically regulated in a sex- and depot-dependent manner. In male mice, the frequency of $\mathrm{Zfp} 423^{+}$ mural cells is higher and more robustly activated by high-fat diet feeding in the gonadal depot than in the inguinal depot; this correlates well with the hyperplastic potential of the depots in obesity (Vishvanath et al. 2016). A number of questions remain unanswered about this precursor population. It is unclear whether these cells proliferate prior to undergoing differentiation or whether the number of $\mathrm{Zfp} 423^{+}$mural cells increases by virtue of activating $Z f p 423$ expression in additional Pdgfr $\beta^{+}$cells. Furthermore, it remains unclear what signals activate these cells and/or Zfp423 expression in response to high-fat diet feeding.

The identification of perivascular adipose precursors is consistent with historical observations that primitive adipocytes are associated with the vasculature. However, direct lineage tracing evidence in support of this hypothesis has been lacking. In the modern era of developmental biology, bona fide lineage tracing is best achieved by using an inducible Cre/lox recombination system for "pulse-

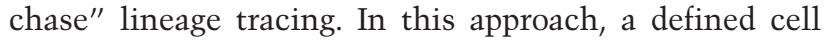


population is irreversibly marked by the expression of a Cre-dependent reporter (usually LacZ or fluorescent protein) at a selected time ("pulse labeling"). This is achieved by transient activation of Cre recombinase. Marked cells are then detected at later time points to determine how the originally labeled precursors contribute to specific cell types ("chase"). Recently, we and others used lineage tracing models to evaluate the contribution of mural preadipose populations to the maintenance and expansion of the adipocyte pool in adults (Jiang et al. 2014; Berry et al. 2016; Vishvanath et al. 2016). Jiang et al. (2014) used SMACreERT2 mice to evaluate the contribution of $\mathrm{SMA}^{+} \mathrm{mu}-$ ral cells to the maintenance of adipose tissue mass in lean animals. Lineage tracing indicated that the adipocyte pool in adult mice is maintained at least in part through differentiation of $\mathrm{SMA}^{+}$mural APCs. In fact, these cells appear critical for maintaining adipose tissue mass; inducible deletion of Ppary in these cells leads to progressive lipoatrophy and a lipodystrophic-like metabolic phenotype (Jiang et al. 2014).

Our group has recently derived a novel doxycycline-inducible mural cell lineage tracking system in which the
Pdgfr $\beta$ promoter ultimately drives Cre expression (Fig. 2; Vishvanath et al. 2016). Using this system (termed the "MuralChaser" mouse), we asked whether Pdgfr $\beta^{+}$mural cells contribute to adipocyte hyperplasia associated with diet-induced obesity. Indeed, we identified several mural cell-derived adipocytes in visceral WAT depots formed during the high-fat diet feeding period (Vishvanath et al. 2016). In agreement with prior lineage tracing studies described above, adipocyte hyperplasia was not observed in the inguinal WAT depot of male mice (Wang et al. 2013). These data provide direct genetic evidence that perivascular preadipocytes contribute to adipocyte hyperplasia in obesity. This is in line with fate-mapping studies of perivascular nestin ${ }^{+}$cells in the adipose tissue (NestinCre; Rosa26R ${ }^{\text {tdTomato }} /$, revealing the presence of labeled gonadal adipocytes following high-fat diet (Iwayama et al. 2015). It is currently unclear whether the adipogenic capacity of perivascular preadipocytes cells is critical for healthy WAT expansion in the setting of obesity. Functional manipulation of adipogenic signaling pathways (e.g., Ppar $\gamma$ deletion) in Pdgfr $\beta^{+}$cells will help clarify the importance of this population.
A

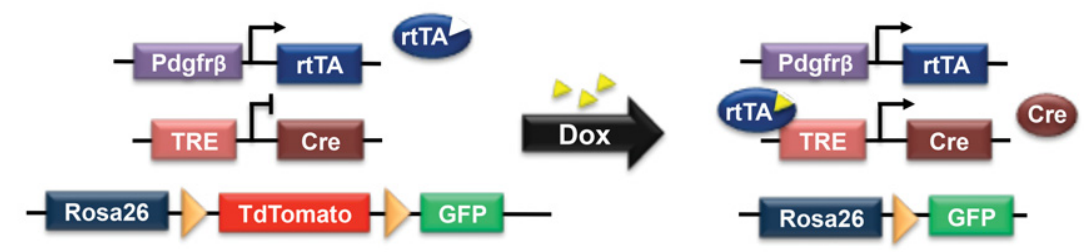

B
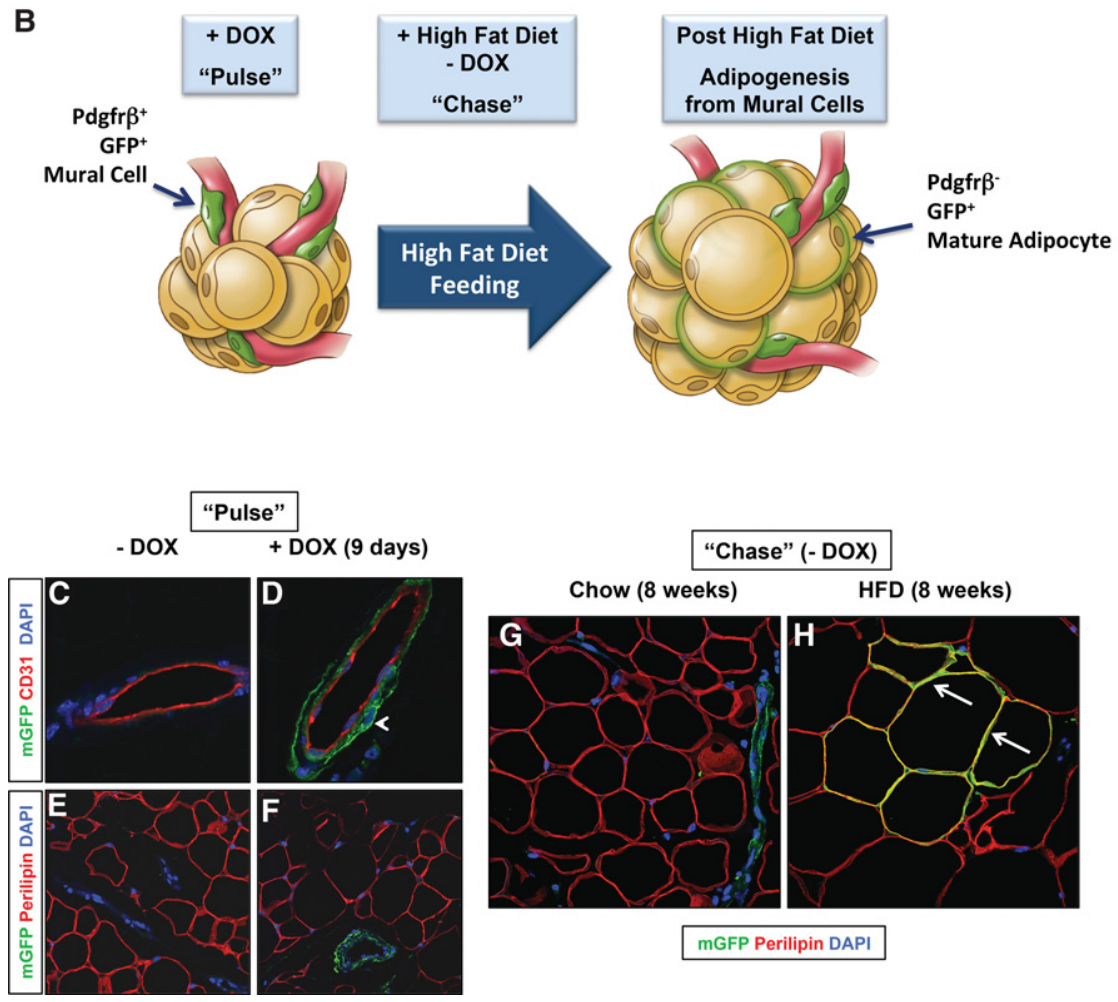

Figure 2. Tracking de novo adipocyte differentiation using the MuralChaser model. (A) Genetic alleles comprising the MuralChaser lineage tracing system. In the presence of doxycycline (DOX), rtTA activates Cre expression. Cre excises the loxPflanked membrane tdTomato cassette and allows constitutive activation of membrane GFP $(m G F P)$ reporter expression. $(B)$ "Pulse-chase" lineage tracing approach. Doxycycline-containing food was administered to MuralChaser mice for $9 \mathrm{~d}$ to label Pdgfr $\beta^{+}$cells ("pulse"). Animals were then switched to a high-fat diet (HFD) or chow diet for $8 \mathrm{wk}$ in the absence of doxycycline (chase). GGFP $^{+}$adipocytes represent de novo differentiated fat cells formed during the 8-wk period. $(C, D)$ Administration of doxycycline to MuralChaser mice for $9 \mathrm{~d}$ resulted in doxycycline-dependent mGFP labeling (arrowhead) of $\operatorname{Pdgfr} \beta^{+}$cells lining the endothelium $\left(\mathrm{CD} 31^{+}\right)$of adipose tissue ("pulse"). $(E, F)$ mGFP labeling was not found in mature adipocytes (perilipin ${ }^{+}$). $(G, H)$ Following 8 wk of high-fat diet feeding, numerous $\mathrm{mGFP}^{+}$perilipin ${ }^{+}$adipocytes were observed (arrows). These cells represent de novo differentiated adipocytes formed during the 8-wk period. Portions of this figure were reproduced with data from Vishvanath et al. (2016), with permission from Elsevier. 


\section{Bone marrow LepR ${ }^{+}$perivascular cells}

Adipogenesis occurs within skeletal bone marrow in response to a number of physiological and pharmacological conditions. Adipocyte accumulation is strongly associated with decreased osteogenesis; however, the signals that influence the balance between the two lineages have remained unclear. Morrison and colleagues (Zhou et al. 2014) identified a subpopulation of multipotent perivascular stem cells defined by the expression of the leptin receptor (LepR). LepR ${ }^{+}$cells emerge postnatally and represent a majority of the colony-forming cells in the bone marrow (Zhou et al. 2014). They actively express Pdgfra, Pdgfr $\beta$, and Nestin and are targeted by Prx1-Cre mice. These cells are quiescent but proliferate robustly after injury. Lineage analysis indicates that $\mathrm{LepR}^{+}$perivascular cells are multipotent, giving rise to most adipocytes and osteoblasts accumulating after irradiation or fracture (Zhou et al. 2014). LepR ${ }^{+}$cells also give rise to marrow adipocytes accumulating with age. Importantly, $\mathrm{LepR}^{+}$cells serve as a hematopoietic stem cell niche, secreting cytokines that promote stem cell maintenance (Ding et al. 2012).

Recently, Yue et al. (2016) determined that LepR signaling itself plays an important role in the cell fate decision of $\mathrm{LepR}^{+}$cells. Leptin signaling in Prxl lineage cells promotes marrow adipogenesis and inhibits osteogenesis in response to high-fat diet feeding. Interestingly, loss of LepR signaling had no impact on adipogenesis induced by irradiation. This indicates that multiple mechanisms control the fate of LepR ${ }^{+}$cells in skeletal bone marrow.

Potential circulating bone marrow-derived progenitors It is generally assumed that adipocyte precursors reside in close proximity to the sites of adipocyte accumulation. A number of studies have now challenged this assumption, suggesting that circulating bone marrow-derived cells may differentiate into adipocytes under certain conditions (Ryden et al. 2015; Gavin et al. 2016). This hypothesis emerged largely from the work of Klemm and colleagues (Majka et al. 2010) that demonstrated the production of adipocytes from bone marrow-derived progenitor cells in the major fat depots of mice. Bone marrow progenitor (BMP)-derived adipocytes preferentially accumulated in visceral fat depots of mice in response to high-fat diet feeding or treatment with the Ppary agonist rosiglitazone. This hypothesis has been elegantly explored in humans as well. Gavin et al. (2016) and Ryden et al. (2015) demonstrated the presence of donor BMP-derived adipocytes in human subjects undergoing bone marrow transplantation, contributing to up to $10 \%$ of the adipocyte population in adipose tissues. Some lineage tracing studies in mice have not supported the notion of a myeloid origin of adipocytes, at least during normal development (Berry and Rodeheffer 2013). However, it is certainly plausible that, under specific insults such as bone marrow irradiation and transplantation, these BMPs give rise to a subset of adipocytes and contribute to adipose expansion or remodeling. The isolation and characterization of these putative BMPs will be critical for the advancement of this hypothesis.
Adipose Dlk1/Pref1 $1^{+}$cells Perhaps the first described "preadipocyte marker" is the preadipocyte-secreted EGF repeat-containing protein Dlk1/Pref1 (Smas and Sul 1993; Smas et al. 1997; Hudak and Sul 2013). Studies originally performed in cell lines indicated that Dlk 1 is expressed in preadipocytes, where it acts as a molecular break on adipogenesis. Dlk1 is expressed in only the preadipocyte and not the mature adipocyte; thus, in principle, the expression of this gene can help localize APCs in vivo. Indeed, lineage tracing using Dlk1-CreERT2 mice reveals that dermal adipocytes descend from embryonic Dlk $1^{+}$ cells. Hudak et al. (2014) used tetracycline-inducible systems to isolate, localize, and trace Dlk $1^{+}$cells. They revealed that $\mathrm{Dlk} 1^{+}$cells isolated from WAT are highly adipogenic. These cells exhibited the cell surface prolife of CD24 ${ }^{+}$APCs and did not express mural cell markers or Zfp423 and Ppar $\gamma$, suggesting that this population is a very early mesenchymal precursor that likely overlaps with the CD24+ APCs identified by Friedman and colleagues (Rodeheffer et al. 2008).

$\mathrm{Dlk} 1^{+}$precursors first appear in the dorsal mesenteric region around embryonic day 10.5 (E10.5) of mouse development and give rise to inguinal and gonadal WAT (Hudak et al. 2014). Ablation of fetal Dlk $1^{+}$cells through Dlk1driven diphtheria toxin expression leads to postnatal lipoatrophy. This study did not report Dlk $1^{+}$lineage tracing results under obesogenic conditions in adult mice; however, ablation of Dlk $1^{+}$cells in adult animals prevented the normal expansion of WAT depots following high-fat diet feeding. Interestingly, inguinal WAT also failed to fully expand in mice lacking Dlk $1^{+}$cells. This depot expands predominantly by adipocyte hypertrophy rather than adipocyte hyperplasia. As such, whether the failure of WAT depots to expand in these animals is due to the loss of adipocyte hyperplasia or the loss of the Dlk $1^{+}$cells per se is unclear. Other functions of $\mathrm{Dlk} 1^{+}$precursors in WAT may exist.

\section{Fetal vs. adult adipose precursors}

An emerging concept in the field is the notion that the precursor populations used in the initial development of adipose tissue ("organogenesis") are molecularly and developmentally distinct from precursor populations used in adult animals for the maintenance and expansion of adipose depots. As described above, LepR $^{+}$stem cells in the bone marrow represent adult progenitors that emerge postnatally. In WAT depots of adults, Ppar $\gamma^{+}$precursors reside in a periendothelial position and express mural cell markers; however, fetal Ppar $\gamma^{+}$APCs are devoid of SMA expression and, like fetal Dlk $1^{+}$cells, do not lie in a classic mural position (Tang et al. 2008; Jiang et al. 2014). Furthermore, fetal adipose precursors appear to be molecularly distinct from adult precursors. Hong et al. (2015) revealed that proliferating CD $24^{+}$APCs within the fetal developing inguinal WAT depot surprisingly expressed perilipin and adiponectin. In adults, perilipin and adiponectin expression is almost exclusively confined to the mature adipocyte. Perilipin ${ }^{+} \mathrm{CD} 24^{+}$APCs were found in proximity to the vasculature but not in direct contact with the endothelium. Collectively, these data point to a model in 
which adipose precursors adopt a mural cell phenotype postnatally as they reside in their vascular niche. Interestingly, Jiang et al. (2014) provided data to suggest that adult mural precursors may be entirely distinct in origin, specified to an adipose fate even before the adipose precursors contributing to the fetal development of WAT.

Recent genetic analyses of adipogenic regulators indicate that the regulatory mechanisms required for adipose tissue formation during fetal/early postnatal development are distinct from those required in adult animals for the recruitment of new adipocytes. For example, Akt2 is dispensable for adipose tissue development but required for CD24 $4^{+}$APC proliferation in postnatal animals (Jeffery et al. 2015). Moreover, C/ebpa is surprisingly dispensable for the maturation and maintenance of adipose tissue formed during fetal and early postnatal development (Wang et al. 2015). However, when C/ebpa inactivation is triggered in adipocytes of adult mice, white, but not beige, adipogenesis is impaired. These results illustrate the complexity of adipose development in vivo and stress the need to study adipose tissue development in various physiological contexts.

\section{Development of thermogenic adipocytes and their precursors}

\section{Development of brown adipose tissue}

In rodents, BAT depots form during fetal development prior to most other adipose depots (for review, see Wang and Seale 2016). Clusters of interscapular brown adipocytes are detectable by E14.5. The thermogenic capacity of BAT depots is fully functional by birth, providing newborns with the ability to acclimatize to the cold. In adult mice, the major BAT depots are located in the dorsal anterior region and consist of the interscapular, cervical, and axillary BAT. These depots can expand further through adipocyte hyperplasia in animals challenged to prolonged cold exposure (Lee et al. 2015b). Infant humans also have interscapular and perirenal BAT that has a molecular profile similar to that of rodent interscapular BAT (Lidell et al. 2013).

Fate-mapping studies in mice indicate that most brown adipocytes in the dorsal BAT depots are likely of paraxial mesoderm origin. Inducible lineage analyses showed that cells marked by homeobox gene engrailed 1 (En1) expression at E8.5-E9.5 give rise to brown adipocytes in anterior depots (Atit et al. 2006). Similar studies indicate that brown adipocytes also descend from cells once expressing myogenic factor $5(M y f 5)$ and paired box 7 (Pax 7$)$, which encode two transcription factors that define myogenic precursors and regulate skeletal myogenesis (Seale et al. 2008; Lepper and Fan 2010). These data were surprising, as BAT and WAT were long believed to derive from a common "adipoblast." The notion that BAT and skeletal muscle are closely related in development is supported by molecular and functional analyses (Timmons et al. 2007). Brown adipocyte precursor cells express many skeletal muscle-specific genes. In addition, the mitochondrial proteome of brown adipocytes is more similar to that of muscle cells than to white adipocytes (Forner et al. 2009). Importantly, manipulation of key transcription factors and microRNAs reveals that muscle cells and brown fat cells can readily undergo a cell fate switch (for review, see Wang and Seale 2016).

\section{Recruitment of beige adipocytes in adults}

It has long been recognized that WAT depots of cold-exposed rodents can undergo extensive remodeling and adopt a thermogenic phenotype elicited by the emergence of UCP1 ${ }^{+}$multilocular adipocytes (Loncar 1991). However, the aforementioned lineage tracing reveals that most $\mathrm{UCP}^{+}$cells within WAT depots are not derived from a $\mathrm{Myf}^{+}$lineage, suggesting a developmental origin largely distinct from the fetal-derived brown adipocytes (Seale et al. 2008; Sanchez-Gurmaches and Guertin 2014). Cold-induced multilocular $\mathrm{UCP}^{+}$adipocytes appear to be molecularly and likely functionally distinct from brown adipocytes present in brown adipose depots. Beige cells appear to exhibit properties of both white and brown adipocytes; therefore, these cells are now widely designated as "beige adipocytes." Cells closely resembling beige adipocytes are present in adult humans, particularly in supraclavicular and paravertebral regions (Sharp et al. 2012; Shinoda et al. 2015).

A great number of pharmacological and physiological stimuli can trigger beige adipocyte accumulation in rodents and humans beyond cold exposure, including cancer cachexia, gastric bypass, exercise, and burn trauma (Kir et al. 2014; Neinast et al. 2015; Sidossis et al. 2015; Stanford et al. 2015). Great progress has been made in elucidating the transcriptional machinery and signaling cascades driving brown and beige adipocyte accumulation; however, in most cases, the actual cellular origin of the UCP1 ${ }^{+}$ adipocytes accumulating under physiological conditions or in genetic models has remained unclear. Multiple lineage tracing studies now indicate that $\mathrm{UCP} 1^{+}$cells naturally appear rapidly and arise predominantly, but not exclusively, by de novo beige adipogenesis in response to $33 \mathrm{AR}$ agonism or cold exposure (Wang et al. 2013; Berry et al. 2016; Shao et al. 2016; Vishvanath et al. 2016). It has also been observed that beige adipocytes have the capacity to revert to a white adipocyte phenotype; the cells lose UCP1 expression and become unilocular when animals are returned to thermoneutral conditions following cold exposure (Rosenwald et al. 2013). These same adipocytes can then revert back to $\mathrm{UCP} 1^{+}$cells upon re-exposure to cold. This interconversion of phenotypes is often referred to as "transdifferentiation" (Barbatelli et al. 2010). Classically, transdifferentiation most often refers to a direct conversion of one differentiated cell type into another in the absence of dedifferentiation; this type of event is difficult to prove experimentally. Some have postulated that the white-to-beige phenotype switching may simply reflect beige adipocytes in active and inactive ("dormant") thermogenic states (Kajimura et al. 2015). It should be noted that current adipocyte lineage tracing approaches do not distinguish between these two possibilities. The adiponectin promoter used for adipocyte targeting is expressed 
in nearly all types of adipocytes. Clear molecular markers discriminating between unilocular white and unilocular dormant beige adipocytes are still needed. As such, the current data support at least two general mechanisms that lead to the natural formation of beige adipocytes during cold exposure: (1) de novo differentiation from precursors and (2) conversion of unilocular adipocytes in multilocular UCP $1^{+}$adipocytes (activation of "dormant" unilocular beige adipocytes and/or transdifferentiation).

There is now tremendous interest in elucidating the cellular origin of beige adipocytes. Long et al. (2014) first revealed that beige adipocytes express a smooth musclelike gene program akin to how classical brown adipocytes exhibit a skeletal muscle-like gene signature. Functional studies also suggest a lineage relationship between beige adipocytes and smooth muscle cells. Stromal vascular cells deficient in Myocardin-related transcription factor $A(M R T F A)$ exhibit less of a smooth muscle-like phenotype and more readily undergo beige adipogenesis (McDonald et al. 2015). Multiple lines of lineage tracing evidence further suggest a smooth muscle origin of beige adipocytes (Long et al. 2014; Berry et al. 2016). Inguinal beige adipocytes rapidly emerging (within $7 \mathrm{~d}$ ) upon cold exposure descend from cells expressing SMA. Furthermore, at least a subpopulation of beige adipocytes formed

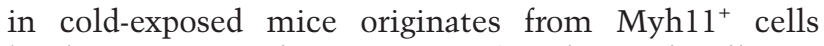
(Myh11-CreERT2 lineage tracing) and mural cells expressing Pdgfr $\beta$ (MuralChaser lineage tracing). However, beige adipocytes originating from $\mathrm{Myh} 1^{+}$and $\mathrm{Pdgfr} \beta^{+}$ cells appeared only after 2 wk of cold exposure (Berry et al. 2016; Vishvanath et al. 2016). These data suggest that multiple waves of beige adipogenesis may occur, each drawing on somewhat distinct perivascular precursor populations.

\section{Brown and beige adipocyte precursors}

Prospective approaches for isolating brown and beige adipose precursors are also starting to emerge (Wang et al. 2014). Wang et al. (2014) revealed that fetal brown adipogenic precursor activity is confined to Pdgfra ${ }^{+}$cells among the Myf5-Cre lineage-marked cells. The committed brown preadipose fraction of this population can be further selected by the expression of Ebf2, a key regulator of brown adipocyte determination (Rajakumari et al. 2013). Ebf2-expressing cells purified from Ebf2-GFP reporter embryos or adult brown fat tissue from Ebf2-GFP reporter mice uniformly differentiate into brown adipocytes but not muscle cells. Analysis of Ebf2 expression during fetal development indicates that Ebf2 expression was first detected in Myf5 lineage cells in anterior somites. At this stage, Ebf 2 and MyoD were expressed in distinct Myf5 lineage cells, suggesting that brown adipocyte and myogenic precursors have undergone lineage commitment by the time that Ebf2 protein expression is detectable.

Analysis of clonal cell lines derived from cultured inguinal WAT SVF first indicated the presence of cells that can differentiate into either white or dormant beige adipocytes with thermogenic potential. This suggests the pres- ence of committed beige precursors within the adult adipose stromal compartment (Wu et al. 2012). However, selective markers for the prospective isolation of native beige cell precursors from adipose tissues have been elusive. Wang et al. (2014) revealed that Ebf2 expression could also identify beige adipose precursors in the inguinal WAT depot of mice. Upon cold exposure or $\beta 3$ AR agonism, the frequency of Ebf $2^{+}$; $\mathrm{Pdgfra}{ }^{+}$cells in the inguinal WAT, but not gonadal WAT, depot increases. Ebf2 ${ }^{+}$; $\mathrm{Pdgfra}^{+}$, but not Ebf2 ${ }^{-}$;Pdgfra ${ }^{+}$, cells isolated from cold-exposed mice differentiate in $\mathrm{Ucp}^{+}{ }^{+}$adipocytes, further suggesting that these cells represent native beige adipose precursors (Wang et al. 2014).

A number of critical questions remain regarding the exact identity of beige adipocyte precursors and their relationship to white adipocyte precursors. In particular, it remains unclear whether Ebf2 ${ }^{+}$and Ebf2 ${ }^{-}$Pdgfra $^{+}$cells represent distinct mesenchymal cell types/lineages that diverged much earlier in development. Alternatively, beige and white adipocytes may originate from bipotent/ multipotent Pdgfra ${ }^{+}$progenitors to give rise to $\mathrm{Ebf} 2^{+}$and Ebf2- preadipocytes. Importantly, it is unclear how Ebf $2^{+}$precursors fit into the lineage tracing results described above; the exact localization of these cells and the cell type that they represent in vivo are unclear.

It also remains unclear how beige precursors are activated to differentiate upon activation of the sympathetic nervous system. $\beta 3 \mathrm{AR}$ expression appears confined largely to the mature adipocytes; therefore, non-cell-autonomous mechanisms are likely in place. A number of studies in recent years now suggest that catecholamine-triggered beige adipogenesis is coordinated and facilitated by the innate immune system. Lee et al. (2016) demonstrate that bipotent gonadal WAT Pdgfra ${ }^{+}$cells localize to sites of M2 macrophages upon cold exposure and suggest that lipids from a subpopulation of adjacent macrophages may trigger adipogenesis through activation of Ppary. Lee et al. (2015a) and Brestoff et al. (2015) unveiled an adipose type- 2 innate immune response driven by the sympathetic nervous system in response to cold exposure. In this proposed model, ILC2s, eosinophils, and macrophages produce cytokines such as IL-13, IL-4, and Met-enkephalin, all of which act directly on adipose precursors to drive proliferation and/or differentiation (Qiu et al. 2014; Brestoff et al. 2015; Lee et al. 2015a). The exercise-induced myokine Meteorin-like stimulates beige adipocyte accumulation in inguinal WAT through an eosinophil-/macrophage-dependent mechanism (Rao et al. 2014). Thus, this immune cell relay mechanism also appears operative in exercise-induced beiging. Additional insight into the exact identity of beige precursors and the development of more specific tools to target these cells will be essential to further our understanding of beige adipocyte formation in adult animals.

\section{Perspectives, limitations, and future directions}

Adipose tissue is unique in its remarkable capacity to expand or remodel in various physiological settings. 
Adipocytes are known mostly for their role in energy metabolism; however, it is now clear that the emergence of adipocytes in tissues beyond adipose impacts local tissue regeneration, homeostasis, stem cell activity, and pathologies. There is now considerable interest in harnessing the tremendous plasticity of the adipose lineage for therapeutic benefit. Potential avenues include lineage reprogramming of energy-storing white adipocytes to energy-burning brown/beige adipocytes and/or altering the development of white adipocytes to impact adipose distribution and tissue regeneration in adults. A deeper understanding of the developmental origins of all adipocytes and the identities of their precursors will be critical to these efforts.

For decades, adipose biologists have relied exclusively on immortalized or primary cultures of preadipose cells induced to differentiate in vitro by robust proadipogenic stimuli. As a result, many have perhaps grown accustomed to thinking of the adipose life cycle in terms of "preadipocytes" and "mature adipocytes." Here we describe recent efforts to identify native adipose precursor populations leading to the development, maintenance, and expansion of adipocytes in different physiological settings. Some of these different studies may appear conflicting, particularly as they relate to exact cell types that APCs represent as well as their localization in vivo (i.e., periendothelial or not periendothelial). In our view, most of these data are not mutually exclusive, since we cannot rule out the possibility that multiple populations may exist. Here we present each population as it was identified and characterized; however, it is important to note that there is likely significant overlap in the reported precursor populations. Furthermore, stable APC populations with intermediate phenotypes may exist, reflecting an adipose precursor hierarchy (e.g., CD24 ${ }^{+}$and CD24- APCs). Alternatively, each precursor population may exhibit a specialized role in adipose biology. The exact precursor population drawn on to undergo adipogenesis may depend on the sex, location, age, or proadipogenic stimulus. At the very least, the studies described here indicate that adipose precursors, much like the adipocytes themselves, are likely heterogeneous. The vast complexity of the adipose lineage is increasingly more apparent as lineage tracing results continue to be reported. As such, additional distinct precursor populations are likely to emerge.

Studies pertaining to dermal and bone marrow stem cells indicate that one should not assume that the sole function of APCs is to give rise to adipocytes. Cells similar or related to the APC populations described here have also been implicated in the regulation of inflammation, angiogenesis, and stem cell maintenance through cytokine production. A major challenge going forward will be to determine the exact requirement of the various precursor populations described here. This will be best achieved by the development of genetic tools for temporal control of gene expression in these populations. Current inducible Cre/loxP models, such as the MuralChaser mice, may prove useful in exploring the adipose precursor niche, determining how the precursors are regulated by the microenvironment, and examining the functional conse- quences of manipulating these cells on adipose development and their neighboring cells.

The development of genetic tools and FACS-based approaches to isolate adipose precursors gives plenty of reason for optimism in this growing field; however, there are still significant limitations to the current approaches that must be addressed going forward. In fact, some of these limitations may explain the inherent discrepancies in published lineage tracing results. Notably, many lineage tracing studies have used transgenic lines in which Cre activity is constitutive. The use of constitutively active Cre lines can be limiting in a number of ways. When bred to a Cre-dependent Rosa26R reporter strain, reporter expression is subsequently activated in promoter-expressing cells and maintained in all descending cells; this occurs regardless of whether descending cells continue to express the promoter of interest. Therefore, it becomes difficult to directly assess whether adipogenesis originates from cells actively expressing the promoter of interest during development. Moreover, the lack of temporal control over Cre activity prevents the use of these strains to determine the contribution of putative precursors to adipocyte hyperplasia under specific physiological conditions postnatally. Another important limitation is in the nature of the promoters ultimately driving Cre expression. The expression of Pdgfr $\beta$, Pdgfra, Ppary (all of which have been used for lineage tracing), and other markers is not entirely restricted to one cell type in mice. This can become an issue in attempts to manipulate gene expression in different precursor populations, as confounding nonadipose phenotypes may emerge that indirectly affect adipogenesis. Unfortunately, a single marker that unambiguously identifies native APCs has yet to be identified.

As described above, genetic "pulse-chase" lineage tracing is currently the most precise way to establish clear lineage relationships. These approaches most often use doxycyline-inducible/suppressible systems for regulated Cre expression or animals expressing tamoxifen-inducible CreERT2. Both systems have been powerful in this field; however, they, too, have concerning limitations. Tamoxifen is a well-known inhibitor of estrogen receptor activity. The estrogen receptor itself plays an important role in adipose tissue remodeling (Davis et al. 2013; Palmer and Clegg 2015). At certain doses, tamoxifen can elicit detrimental effects on adipose tissue and remain localized in the adipocyte nucleus well beyond removal of the ligand (Ye et al. 2015). These effects include rapid cell death followed by adipose regeneration via de novo adipocyte differentiation. Liu et al. (2015) made similar observations and suggested that tamoxifen triggers adipocyte death through the inappropriate accumulation of reactive oxygen species. Moreover, Kloting and colleagues (Hesselbarth et al. 2015) observed that tamoxifen treatment itself impacts body composition and glucose and lipid homeostasis and alters adipose tissue cellularity. Notably, the investigators observed that tamoxifen treatment triggers substantial browning of the subcutaneous depot. This artificial turnover/adipogenesis is significant, as it can directly confound the interpretation of lineage tracing experiments. 
There are also adverse effects of chronic doxycycline treatment on metabolism. Auwerx and colleagues (Chatzispyrou et al. 2015; Moullan et al. 2015) demonstrated that doxycycline negatively impacts mitochrondrial function. Doxycycline can also impact the gut microbiota in humans; the direct impact of this on adipose biology is unclear but potentially significant (Angelakis et al. 2014). Furthermore, doxycycline can regulate the function of matrix metalloproteinases (Stechmiller et al. 2010). Nevertheless, we are presently unaware of data that would suggest that short-term doxycycline exposure directly impacts adipose tissue turnover in a manner that would confound lineage tracing studies. Moreover, doxycycline leaves the system shortly after removal of doxycyclinecontaining food or water; expression of the widely used TRE-Cre transgene turns off within $24 \mathrm{~h}$ of removing doxycycline (Wang et al. 2013). This precise and verifiable temporal control over Cre expression is essential for lineage tracing analysis. As such, it is our position that the Teton systems are preferable over the tamoxifen-based Cre induction systems when performing adipose lineage tracing studies. At the very least, great caution must be taken in interpreting lineage tracing results when using tamoxifen; its action on the estrogen receptor in adipose tissue and its potential to trigger cell turnover must be considered.

Our discussion here focused on recent advancements in murine adipose precursor biology. It is important to note that some of the representative subcutaneous and visceral depots explored in mouse models are not direct correlates of human depots commonly studied. Human adipose precursors certainly share at least some characteristics with the murine populations studied here. Of note, an increasing number of studies point to the mural cell compartment of the vasculature as a home for mesenchymal stem cells and/or adipose precursors in various human tissues (Crisan et al. 2008; Zimmerlin et al. 2010; Yuan et al. 2014). Better FACS-based approaches allowing for more selective purification of human adipocyte precursor subpopulations will be needed. New strategies to isolate human adipose precursors may also help in exploring adipogenesis in disorders beyond obesity, including lipodystrophy.

It is increasingly apparent that the developmental biology of adipose tissues is quite complex. Considerably more effort, facilitated by more specific genetic tools and antibodies, will be needed to fully sort out the adipose lineage and the role of adipose precursors in various aspects of physiology and disease. In the end, further insight into the biology of adipose precursors may lead to novel therapeutic strategies that target the adipose lineage and combat various diseases.

\section{Acknowledgments}

We apologize to our colleagues in the field for not being able to discuss all of the outstanding and important studies related to adipose tissue remodeling and adipose precursors. We thank $\mathrm{P}$. Scherer for critical reading of the manuscript, and members of the Touchstone Diabetes Center at University of Texas Southwestern for useful discussion. R.K.G. is supported by National Institute of Diabetes and Digestive and Kidney Diseases R01
DK104789, and C.H. is supported by the National Institutes of Health National Institute of General Medical Sciences training grant T32 GM008203. Graphic illustrations in this review were designed by Visually Medical (http://www.visuallymedical.com).

\section{References}

Alexander CM, Kasza I, Yen CL, Reeder SB, Hernando D, Gallo RL, Jahoda CA, Horsley V, MacDougald OA. 2015. Dermal white adipose tissue: a new component of the thermogenic response. J Lipid Res 56: 2061-2069.

Angelakis E, Million M, Kankoe S, Lagier JC, Armougom F, Giorgi R, Raoult D. 2014. Abnormal weight gain and gut microbiota modifications are side effects of long-term doxycycline and hydroxychloroquine treatment. Antimicrob Agents Chemother 58: 3342-3347.

Atit R, Sgaier SK, Mohamed OA, Taketo MM, Dufort D, Joyner AL, Niswander L, Conlon RA. 2006. $\beta$-Catenin activation is necessary and sufficient to specify the dorsal dermal fate in the mouse. Dev Biol 296: 164-176.

Barbatelli G, Murano I, Madsen L, Hao Q, Jimenez M, Kristiansen K, GiacobinoJP,De Matteis R, CintiS. 2010. The emergence of coldinduced brown adipocytes in mouse white fat depots is determined predominantly by white to brown adipocyte transdifferentiation. Am J Physiol Endocrinol Metab 298: E1244-E1253.

Berry R, Rodeheffer MS. 2013. Characterization of the adipocyte cellular lineage in vivo. Nat Cell Biol 15: 302-308.

Berry R, Rodeheffer MS, Rosen CJ, Horowitz MC. 2015. Adipose tissue residing progenitors (adipocyte lineage progenitors and adipose derived stem cells (ADSC). Curr Mol Biol Rep 1: 101-109.

Berry DC, Jiang Y, Graff JM. 2016. Mouse strains to study cold-inducible beige progenitors and beige adipocyte formation and function. Nat Commun 7: 10184.

Billon N, Dani C. 2012. Developmental origins of the adipocyte lineage: new insights from genetics and genomics studies. Stem Cell Rev 8: 55-66.

Brestoff JR, Kim BS, Saenz SA, Stine RR, Monticelli LA, Sonnenberg GF, Thome JJ, Farber DL, Lutfy K, Seale P, et al. 2015. Group 2 innate lymphoid cells promote beiging of white adipose tissue and limit obesity. Nature 519: 242-246.

Cawthorn WP, Scheller EL, MacDougald OA. 2012. Adipose tissue stem cells meet preadipocyte commitment: going back to the future. J Lipid Res 53: 227-246.

Chatzispyrou IA, Held NM, Mouchiroud L, Auwerx J, Houtkooper RH. 2015. Tetracycline antibiotics impair mitochondrial function and its experimental use confounds research. Cancer Res 75: 4446-4449.

Chau YY, Bandiera R, Serrels A, Martinez-Estrada OM, Qing W, Lee M, Slight J, Thornburn A, Berry R, McHaffie S, et al. 2014. Visceral and subcutaneous fat have different origins and evidence supports a mesothelial source. Nat Cell Biol 16: 367-375.

Chawla A, Lazar MA. 1994. Peroxisome proliferator and retinoid signaling pathways co-regulate preadipocyte phenotype and survival. Proc Natl Acad Sci 91: 1786-1790.

Cinti S. 2009. Reversible physiological transdifferentiation in the adipose organ. Proc Nutr Soc 68: 340-349.

Cinti S, Cigolini M, Bosello O, Bjorntorp P. 1984. A morphological study of the adipocyte precursor. I Submicrosc Cytol 16: 243-251.

Crisan M, Yap S, Casteilla L, Chen CW, Corselli M, Park TS, Andriolo G, Sun B, Zheng B, Zhang L, et al. 2008. A perivascular origin for mesenchymal stem cells in multiple human organs. Cell Stem Cell 3: 301-313. 
Cristancho AG, Lazar MA. 2011. Forming functional fat: a growing understanding of adipocyte differentiation. Nat Rev Mol Cell Biol 12: 722-734.

Davis KE, Neinast MD, Sun K, Skiles WM, Bills JD, Zehr JA, Zeve D, Hahner LD, Cox DW, Gent LM, et al. 2013. The sexually dimorphic role of adipose and adipocyte estrogen receptors in modulating adipose tissue expansion, inflammation, and fibrosis. Mol Metab 2: 227-242.

Ding L, Saunders TL, Enikolopov G, Morrison SJ. 2012. Endothelial and perivascular cells maintain haematopoietic stem cells. Nature 481: 457-462.

Farmer SR. 2006. Transcriptional control of adipocyte formation. Cell Metab 4: 263-273.

Festa E, Fretz J, Berry R, Schmidt B, Rodeheffer M, Horowitz M, Horsley V. 2011. Adipocyte lineage cells contribute to the skin stem cell niche to drive hair cycling. Cell 146: 761-771.

Forner F, Kumar C, Luber CA, Fromme T, Klingenspor M, Mann M. 2009. Proteome differences between brown and white fat mitochondria reveal specialized metabolic functions. Cell Metab 10: 324-335.

Gavin KM, Gutman JA, Kohrt WM, Wei Q, Shea KL, Miller HL, Sullivan TM, Erickson PF, Helm KM, Acosta AS, et al. 2016. De novo generation of adipocytes from circulating progenitor cells in mouse and human adipose tissue. FASEB $I$ 30: 1096-1108.

Green H, Kehinde O. 1974. Sublines of mouse 3T3 cells that accumulate lipid. Cell 1: 113-116.

Gupta RK, Arany Z, Seale P, Mepani RJ, Ye L, Conroe HM, Roby YA, Kulaga H, Reed RR, Spiegelman BM. 2010. Transcriptional control of preadipocyte determination by Zfp423. Nature 464: 619-623.

Gupta RK, Mepani RJ, Kleiner S, Lo JC, Khandekar MJ, Cohen P, Frontini A, Bhowmick DC, Ye L, Cinti S, et al. 2012. Zfp423 expression identifies committed preadipocytes and localizes to adipose endothelial and perivascular cells. Cell Metab 15: 230-239.

Gustafson B, Gogg S, Hedjazifar S, Jenndahl L, Hammarstedt A, Smith U. 2009. Inflammation and impaired adipogenesis in hypertrophic obesity in man. Am I Physiol Endocrinol Metab 297: E999-E1003.

Han J, Lee JE, Jin J, Lim JS, Oh N, Kim K, Chang SI, Shibuya M, Kim H, Koh GY. 2011. The spatiotemporal development of adipose tissue. Development 138: 5027-5037.

Hepler C, Gupta RK. 2016. The expanding problem of adipose depot remodeling and postnatal adipocyte progenitor recruitment. Mol Cell Endocrinol doi: 10.1016/j.mce.2016.10.011.

Hesselbarth N, Pettinelli C, Gericke M, Berger C, Kunath A, Stumvoll M, Bluher M, Kloting N. 2015. Tamoxifen affects glucose and lipid metabolism parameters, causes browning of subcutaneous adipose tissue and transient body composition changes in C57BL/6NTac mice. Biochem Biophys Res Commun 464: 724-729.

Hong KY, Bae H, Park I, Park DY, Kim KH, Kubota Y, Cho ES, Kim H, Adams RH, Yoo OJ, et al. 2015. Perilipin+ embryonic preadipocytes actively proliferate along growing vasculatures for adipose expansion. Development 142: 2623-2632.

Hudak CS, Sul HS. 2013. Pref-1, a gatekeeper of adipogenesis. Front Endocrinol (Lausanne) 4: 79.

Hudak CS, Gulyaeva O, Wang Y, Park SM, Lee L, Kang C, Sul HS. 2014. Pref-1 marks very early mesenchymal precursors required for adipose tissue development and expansion. Cell Rep 8: 678-687.

Iwayama T, Steele C, Yao L, Dozmorov MG, Karamichos D, Wren JD, Olson LE. 2015. PDGFRa signaling drives adipose tissue fi- brosis by targeting progenitor cell plasticity. Genes Dev 29: 1106-1119.

Jeffery E, Church CD, Holtrup B, Colman L, Rodeheffer MS. 2015. Rapid depot-specific activation of adipocyte precursor cells at the onset of obesity. Nat Cell Biol 17: 376-385.

Jeffery E, Wing A, Holtrup B, Sebo Z, Kaplan JL, Saavedra-Pena R, Church CD, Colman L, Berry R, Rodeheffer MS. 2016. The adipose tissue microenvironment regulates depot-specific adipogenesis in obesity. Cell Metab 24: 142-150.

Jiang Y, Berry DC, Tang W, Graff JM. 2014. Independent stem cell lineages regulate adipose organogenesis and adipose homeostasis. Cell Rep 9: 1007-1022.

Joe AW, Yi L, Natarajan A, Le Grand F, So L, Wang J, Rudnicki MA, Rossi FM. 2010. Muscle injury activates resident fibro/ adipogenic progenitors that facilitate myogenesis. Nat Cell Biol 12: 153-163.

Kajimura S, Spiegelman BM, Seale P. 2015. Brown and beige fat: physiological roles beyond heat generation. Cell Metab 22: 546-559.

Karpe F, Pinnick KE. 2015. Biology of upper-body and lower-body adipose tissue-link to whole-body phenotypes. Nat Rev Endocrinol 11: 90-100.

Kim SM, Lun M, Wang M, Senyo SE, Guillermier C, Patwari P, Steinhauser ML. 2014. Loss of white adipose hyperplastic potential is associated with enhanced susceptibility to insulin resistance. Cell Metab 20: 1049-1058.

Kir S, White JP, Kleiner S, Kazak L, Cohen P, Baracos VE, Spiegelman BM. 2014. Tumour-derived PTH-related protein triggers adipose tissue browning and cancer cachexia. Nature 513: 100-104.

Knittle JL, Timmers K, Ginsberg-Fellner F, Brown RE, Katz DP. 1979. The growth of adipose tissue in children and adolescents. Cross-sectional and longitudinal studies of adipose cell number and size. J Clin Invest 63: 239-246.

Kruglikov IL, Scherer PE. 2016. Dermal adipocytes: from irrelevance to metabolic targets? Trends Endocrinol Metab 27: $1-10$.

Lee MJ, Wu Y, Fried SK. 2010. Adipose tissue remodeling in pathophysiology of obesity. Curr Opin Clin Nutr Metab Care 13: 371-376.

Lee YH, Petkova AP, Mottillo EP, Granneman JG. 2012. In vivo identification of bipotential adipocyte progenitors recruited by $\beta 3$-adrenoceptor activation and high-fat feeding. Cell Metab 15: 480-491.

Lee MJ, Wu Y, Fried SK. 2013. Adipose tissue heterogeneity: implication of depot differences in adipose tissue for obesity complications. Mol Aspects Med 34: 1-11.

Lee MW, Odegaard JI, Mukundan L, Qiu Y, Molofsky AB, Nussbaum JC, Yun K, Locksley RM, Chawla A. 2015a. Activated type 2 innate lymphoid cells regulate beige fat biogenesis. Cell 160: 74-87.

Lee YH, Petkova AP, Konkar AA, Granneman JG. 2015b. Cellular origins of cold-induced brown adipocytes in adult mice. FASEB I 29: 286-299.

Lee YH, Kim SN, Kwon HJ, Maddipati KR, Granneman JG. 2016. Adipogenic role of alternatively activated macrophages in $\beta$ adrenergic remodeling of white adipose tissue. Am I Physiol Regul Integr Comp Physiol 310: R55-R65.

Lepper C, Fan CM. 2010. Inducible lineage tracing of Pax7-descendant cells reveals embryonic origin of adult satellite cells. Genesis 48: 424-436.

Lidell ME, Betz MJ, Dahlqvist Leinhard O, Heglind M, Elander L, Slawik M, Mussack T, Nilsson D, Romu T, Nuutila P, et al. 2013. Evidence for two types of brown adipose tissue in humans. Nat Med 19: 631-634. 
Liu L, Zou P, Zheng L, Linarelli LE, Amarell S, Passaro A, Liu D, Cheng Z. 2015. Tamoxifen reduces fat mass by boosting reactive oxygen species. Cell Death Dis 6: e1586.

Loncar D. 1991. Convertible adipose tissue in mice. Cell Tissue Res 266: 149-161.

Long JZ, Svensson KJ, Tsai L, Zeng X, Roh HC, Kong X, Rao RR, Lou J, Lokurkar I, Baur W, et al. 2014. A smooth muscle-like origin for beige adipocytes. Cell Metab 19: 810-820.

Macotela Y, Emanuelli B, Mori MA, Gesta S, Schulz TJ, Tseng $\mathrm{YH}, \mathrm{Kahn}$ CR. 2012. Intrinsic differences in adipocyte precursor cells from different white fat depots. Diabetes 61: 16911699.

Majka SM, Fox KE, Psilas JC, Helm KM, Childs CR, Acosta AS, Janssen RC, Friedman JE, Woessner BT, Shade TR, et al. 2010. De novo generation of white adipocytes from the myeloid lineage via mesenchymal intermediates is age, adipose depot, and gender specific. Proc Natl Acad Sci 107: 1478114786.

McDonald ME, Li C, Bian H, Smith BD, Layne MD, Farmer SR. 2015. Myocardin-related transcription factor A regulates conversion of progenitors to beige adipocytes. Cell 160: 105-118.

Morgan-Bathke M, Chen L, Oberschneider E, Harteneck D, Jensen MD. 2015. Sex and depot differences in ex vivo adipose tissue fatty acid storage and glycerol-3-phosphate acyltransferase activity. Am I Physiol Endocrinol Metab 308: E830-E846.

Moullan N, Mouchiroud L, Wang X, Ryu D, Williams EG, Mottis A, Jovaisaite V, Frochaux MV, Quiros PM, Deplancke B, et al. 2015. Tetracyclines disturb mitochondrial function across eukaryotic models: a call for caution in biomedical research. Cell Rep 10: 1681-1691.

Napolitano L. 1963. The differentiation of white adipose cells. An electron microscope study. J Cell Biol 18: 663-679.

Neinast MD, Frank AP, Zechner JF, Li Q, Vishvanath L, Palmer BF, Aguirre V, Gupta RK, Clegg DJ. 2015. Activation of natriuretic peptides and the sympathetic nervous system following Roux-en-Y gastric bypass is associated with gonadal adipose tissues browning. Mol Metab 4: 427-436.

Ortega FJ, Mayas D, Moreno-Navarrete JM, Catalan V, GomezAmbrosi J, Esteve E, Rodriguez-Hermosa JI, Ruiz B, Ricart W, Peral B, et al. 2010. The gene expression of the main lipogenic enzymes is downregulated in visceral adipose tissue of obese subjects. Obesity (Silver Spring) 18: 13-20.

Ouchi N, Parker JL, Lugus JJ, Walsh K. 2011. Adipokines in inflammation and metabolic disease. Nat Rev Immunol 11: 85-97.

Palmer BF, Clegg DJ. 2015. The sexual dimorphism of obesity. Mol Cell Endocrinol 402: 113-119.

Poissonnet CM, Burdi AR, Garn SM. 1984. The chronology of adipose tissue appearance and distribution in the human fetus. Early Hum Dev 10: 1-11.

Poznanski WJ, Waheed I, Van R. 1973. Human fat cell precursors. Morphologic and metabolic differentiation in culture. Lab Invest 29: 570-576.

Qiu Y, Nguyen KD, Odegaard JI, Cui X, Tian X, Locksley RM, Palmiter RD, Chawla A. 2014. Eosinophils and type 2 cytokine signaling in macrophages orchestrate development of functional beige fat. Cell 157: 1292-1308.

Rajakumari S, Wu J, Ishibashi J, Lim HW, Giang AH, Won KJ, Reed RR, Seale P. 2013. EBF2 determines and maintains brown adipocyte identity. Cell Metab 17: 562-574.

Rao RR, Long IZ, White JP, Svensson KJ, Lou J, Lokurkar I, Jedrychowski MP, Ruas JL, Wrann CD, Lo JC, et al. 2014. Meteorinlike is a hormone that regulates immune-adipose interactions to increase beige fat thermogenesis. Cell 157: 1279-1291.
Rivera-Gonzalez GC, Shook BA, Andrae J, Holtrup B, Bollag K, Betsholtz C, Rodeheffer MS, Horsley V. 2016. Skin adipocyte stem cell self-renewal is regulated by a PDGFA/AKT-signaling axis. Cell Stem Cell 19: 738-751.

Rodeheffer MS, Birsoy K, Friedman JM. 2008. Identification of white adipocyte progenitor cells in vivo. Cell 135: 240-249.

Rosen ED, Spiegelman BM. 2014. What we talk about when we talk about fat. Cell 156: 20-44.

Rosenwald M, Perdikari A, Rulicke T, Wolfrum C. 2013. Bi-directional interconversion of brite and white adipocytes. Nat Cell Biol 15: 659-667.

Ryden M, Uzunel M, Hard JL, Borgstrom E, Mold JE, Arner E, Mejhert N, Andersson DP, Widlund Y, Hassan M, et al. 2015. Transplanted bone marrow-derived cells contribute to human adipogenesis. Cell Metab 22: 408-417.

Samanta R, Pouliopoulos J, Thiagalingam A, Kovoor P. 2016. Role of adipose tissue in the pathogenesis of cardiac arrhythmias. Heart Rhythm 13: 311-320.

Sanchez-Gurmaches J, Guertin DA. 2014. Adipocytes arise from multiple lineages that are heterogeneously and dynamically distributed. Nat Commun 5: 4099.

Scheller EL, Cawthorn WP, Burr AA, Horowitz MC, MacDougald OA. 2016. Marrow adipose tissue: trimming the fat. Trends Endocrinol Metab 27: 392-403.

Seale P, Bjork B, Yang W, Kajimura S, Chin S, Kuang S, Scime A, Devarakonda S, Conroe HM, Erdjument-Bromage $\mathrm{H}$, et al. 2008. PRDM16 controls a brown fat/skeletal muscle switch. Nature 454: 961-967.

Seale P, Conroe HM, Estall J, Kajimura S, Frontini A, Ishibashi J, Cohen P, Cinti S, Spiegelman BM. 2011. Prdm16 determines the thermogenic program of subcutaneous white adipose tissue in mice. J Clin Invest 121: 96-105.

Shao M, Ishibashi J, Kusminski CM, Wang QA, Hepler C, Vishvanath L, MacPherson KA, Spurgin SB, Sun K, Holland WL, et al. 2016. Zfp423 maintains white adipocyte identity through suppression of the beige cell thermogenic gene program. Cell Metab 23: 1167-1184.

Sharp LZ, Shinoda K, Ohno H, Scheel DW, Tomoda E, Ruiz L, Hu H, Wang L, Pavlova Z, Gilsanz V, et al. 2012. Human BAT possesses molecular signatures that resemble beige/brite cells. PLoS One 7: e49452.

Shinoda K, Luijten $\mathrm{IH}$, Hasegawa Y, Hong H, Sonne SB, Kim M, Xue R, Chondronikola M, Cypess AM, Tseng YH, et al. 2015. Genetic and functional characterization of clonally derived adult human brown adipocytes. Nat Med 21: 389-394.

Shook B, Rivera Gonzalez G, Ebmeier S, Grisotti G, Zwick R, Horsley V. 2016. The role of adipocytes in tissue regeneration and stem cell niches. Annu Rev Cell Dev Biol 32: 609-631.

Sidossis LS, Porter C, Saraf MK, Borsheim E, Radhakrishnan RS, Chao T, Ali A, Chondronikola M, Mlcak R, Finnerty CC, et al. 2015. Browning of subcutaneous white adipose tissue in humans after severe adrenergic stress. Cell Metab 22: 219-227.

Smas CM, Sul HS. 1993. Pref-1, a protein containing EGF-like repeats, inhibits adipocyte differentiation. Cell 73: 725-734.

Smas CM, Chen L, Sul HS. 1997. Cleavage of membrane-associated pref-1 generates a soluble inhibitor of adipocyte differentiation. Mol Cell Biol 17: 977-988.

Spalding KL, Arner E, Westermark PO, Bernard S, Buchholz BA, Bergmann O, Blomqvist L, Hoffstedt J, Naslund E, Britton T, et al. 2008. Dynamics of fat cell turnover in humans. Nature 453: 783-787.

Stanford KI, Middelbeek RJ, Goodyear LJ. 2015. Exercise effects on white adipose tissue: beiging and metabolic adaptations. Diabetes 64: 2361-2368. 
Stechmiller J, Cowan L, Schultz G. 2010. The role of doxycycline as a matrix metalloproteinase inhibitor for the treatment of chronic wounds. Biol Res Nurs 11: 336-344.

Tang W, Zeve D, Suh JM, Bosnakovski D, Kyba M, Hammer RE, Tallquist MD, Graff JM. 2008. White fat progenitor cells reside in the adipose vasculature. Science 322: 583-586.

Timmons JA, Wennmalm K, Larsson O, Walden TB, Lassmann T, Petrovic N, Hamilton DL, Gimeno RE, Wahlestedt C, Baar K, et al. 2007. Myogenic gene expression signature establishes that brown and white adipocytes originate from distinct cell lineages. Proc Natl Acad Sci 104: 4401-4406.

Tontonoz P, Hu E, Spiegelman BM. 1994. Stimulation of adipogenesis in fibroblasts by PPAR $\gamma 2$, a lipid- activated transcription factor. Cell 79: 1147-1156.

Tran KV, Gealekman O, Frontini A, Zingaretti MC, Morroni M, Giordano A, Smorlesi A, Perugini J, De Matteis R, Sbarbati A, et al. 2012. The vascular endothelium of the adipose tissue gives rise to both white and brown fat cells. Cell Metab 15: 222-229.

Uezumi A, Fukada S, Yamamoto N, Takeda S, Tsuchida K. 2010. Mesenchymal progenitors distinct from satellite cells contribute to ectopic fat cell formation in skeletal muscle. Nat Cell Biol 12: 143-152.

Van RL, Bayliss CE, Roncari DA. 1976. Cytological and enzymological characterization of adult human adipocyte precursors in culture. J Clin Invest 58: 699-704.

Van Robin L, Roncari DA. 1977. Isolation of fat cell precursors from adult rat adipose tissue. Cell Tissue Res 181: 197-203.

Vishvanath L, MacPherson KA, Hepler C, Wang QA, Shao M, Spurgin SB, Wang MY, Kusminski CM, Morley TS, Gupta RK. 2016. Pdgfr $\beta$ mural preadipocytes contribute to adipocyte hyperplasia induced by high-fat-diet feeding and prolonged cold exposure in adult mice. Cell Metab 23: 350-359.

Wang W, Seale P. 2016. Control of brown and beige fat development. Nat Rev Mol Cell Biol 17: 691-702.

Wang QA, Tao C, Gupta RK, Scherer PE. 2013. Tracking adipogenesis during white adipose tissue development, expansion and regeneration. Nat Med 19: 1338-1344.

Wang W, Kissig M, Rajakumari S, Huang L, Lim HW, Won KJ, Seale P. 2014. Ebf2 is a selective marker of brown and beige adipogenic precursor cells. Proc Natl Acad Sci 111: 14466-14471.
Wang QA, Tao C, Jiang L, Shao M, Ye R, Zhu Y, Gordillo R, Ali A, Lian Y, Holland WL, et al. 2015. Distinct regulatory mechanisms governing embryonic versus adult adipocyte maturation. Nat Cell Biol 17: 1099-1111.

Wasserman F. 1926. The fat organs of man: development, structure and systematic place of the so-called adipose tissue. $A$ Zellforsch Microskop Anat Abt Histochem 3: 325-329.

Wasserman F. 1960. Electron microscopic investigation of the surface structures of the fat cell and of their changes during depletion of cell. Z Zellforsch Microskop Anat Abt Histochem 52: 778-787.

Wasserman F. 2011. The development of adipose tissue. Compr Physiol: 87-100.

Wu J, Bostrom P, Sparks LM, Ye L, Choi JH, Giang AH, Khandekar M, Virtanen KA, Nuutila P, Schaart G, et al. 2012. Beige adipocytes are a distinct type of thermogenic fat cell in mouse and human. Cell 150: 366-376.

Ye R, Wang QA, Tao C, Vishvanath L, Shao M, McDonald JG, Gupta RK, Scherer PE. 2015. Impact of tamoxifen on adipocyte lineage tracing: inducer of adipogenesis and prolonged nuclear translocation of Cre recombinase. Mol Metab 4: 771-778.

Yuan SM, Guo Y, Zhou XJ, Shen WM, Chen HN. 2014. PDGFR- $\beta^{+}$ perivascular cells from infantile hemangioma display the features of mesenchymal stem cells and show stronger adipogenic potential in vitro and in vivo. Int I Clin Exp Pathol 7: 2861-2870.

Yue R, Zhou BO, Shimada IS, Zhao Z, Morrison SJ. 2016. Leptin receptor promotes adipogenesis and reduces osteogenesis by regulating mesenchymal stromal cells in adult bone marrow. Cell Stem Cell 18: 782-796.

Zhang B, Tsai PC, Gonzalez-Celeiro M, Chung O, Boumard B, Perdigoto CN, Ezhkova E, Hsu YC. 2016. Hair follicles' transit-amplifying cells govern concurrent dermal adipocyte production through Sonic Hedgehog. Genes Dev 30: 2325-2338.

Zhou BO, Yue R, Murphy MM, Peyer JG, Morrison SJ. 2014. Leptin-receptor-expressing mesenchymal stromal cells represent the main source of bone formed by adult bone marrow. Cell Stem Cell 15: 154-168.

Zimmerlin L, Donnenberg VS, Pfeifer ME, Meyer EM, Peault B, Rubin JP, Donnenberg AD. 2010. Stromal vascular progenitors in adult human adipose tissue. Cytometry A 77: 22-30. 


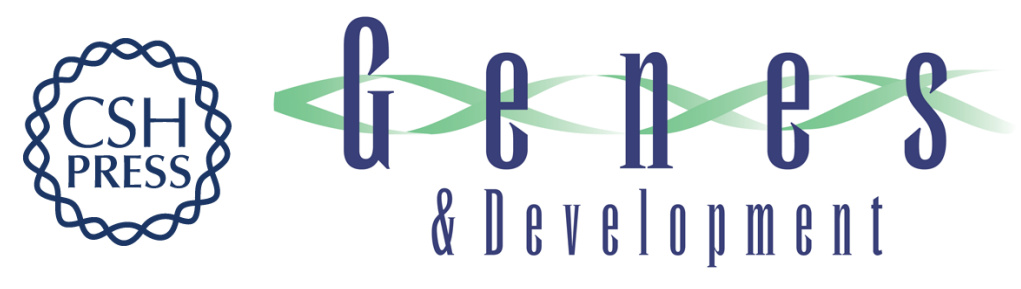

\section{Sorting out adipocyte precursors and their role in physiology and disease}

Chelsea Hepler, Lavanya Vishvanath and Rana K. Gupta

Genes Dev. 2017, 31:

Access the most recent version at doi:10.1101/gad.293704.116

References

Creative

Commons

License

Email Alerting
Service
This article cites 111 articles, 17 of which can be accessed free at: http://genesdev.cshlp.org/content/31/2/127.full.html\#ref-list-1

This article is distributed exclusively by Cold Spring Harbor Laboratory Press for the first six months after the full-issue publication date (see

$\mathrm{http} / / / g e n e s d e v . c s h \mid p . o r g / s i t e / m i s c / t e r m s . x h t m l)$. After six months, it is available under a Creative Commons License (Attribution-NonCommercial 4.0 International), as described at http://creativecommons.org/licenses/by-nc/4.0/.

Receive free email alerts when new articles cite this article - sign up in the box at the top right corner of the article or click here.

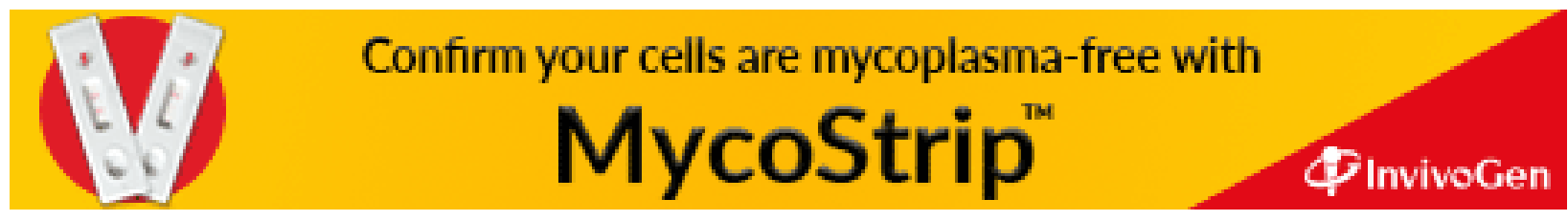

